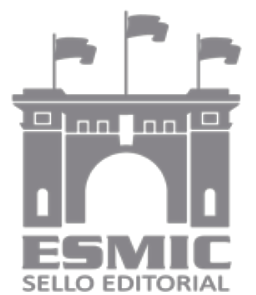

Revista Científica General José María Córdova

ISSN 1900-6586 (impreso), 2500-7645 (en línea)

Volumen 16, Número 21, enero-marzo 2018, pp. 103-120

http://dx.doi.org/10.21830/19006586.300

Citación: Canales Rodríguez, D. E. (2018, enero-marzo). Tráfico ilegal de órganos: retos para la seguridad internacional. Rev. Cient. Gen. José María Córdova, 16 (21), 103-120. DOI: http://dx.doi.org/10.21830/19006586.300

\title{
Tráfico ilegal de órganos: \\ retos para la seguridad internacional
}

Sección: TeCNOCIENCIA

Artículo de investigación científica y tecnológica

\section{Diego Eduardo Canales Rodríguez}

Escuela Superior de Guerra, Bogotá, Colombia

Illegal organ trafficking:

Challenges for international security

Tráfico ilegal de órgãos:

desafios para a segurança internacional

Le trafic illégal d'organes:

des défis à la sécurité internationale

Recibido: 10 de julio de 2017 • Aceptado: 28 de octubre de 2017

* https://orcid.org/0000-0003-0044-8705 - Contacto: canalesd@esdegue.mil.co 
Resumen. Las guerras internas y regionales, la inequidad y la inestabilidad de los gobiernos pueden incrementar el tráfico ilegal de órganos y tejidos humanos. Este tipo de mercado ilegal ha financiado organizaciones criminales que representan un riesgo para la paz y la seguridad internacionales. La comunidad internacional ha promovido acuerdos y protocolos tendientes a disminuir este crimen, sin embargo, estos no se han realizado a través del enfoque de la seguridad. Las fallas en la lucha contra el tráfico de órganos han propiciado la generación de organizaciones criminales, las cuales buscan enriquecerse a costo de las condiciones de salud de las personas menos favorecidas del mundo. Amenazas internacionales como el Estado islámico y otros grupos rebeldes usan el tráfico de órganos como medio para financiar sus actividades. Con el fin de garantizar la seguridad colectiva, se requieren mayores esfuerzos en materia legislativa que permitan fortalecer los programas desarrollados por instituciones como la Europol y la Interpol, con lo cual se lograría la desarticulación de las redes criminales y la asistencia a las víctimas. Palabras clave: cooperación internacional; crimen organizado; desigualdad económica; seguridad internacional; tráfico de órganos.

\begin{abstract}
Internal and regional conflicts, inequality, and government instability can intensify the traffic of human organs and tissue. This type of illegal market has financed criminal organizations, which are a menace to peace and national security. The international community has endorsed agreements and protocols to abate this crime; however, these initiatives lack a focus on security. Shortcomings in the fight against organ trafficking have favored the emergence of criminal organizations seeking to profit at the expense of the health of the less favored worldwide. International threats such as the Islamic State and other rebel groups use organ trafficking as a means to finance their activities. Greater legislative efforts are required to strengthen the programs developed by institutions such as Europol and Interpol to guarantee collective security, leading to the dismantling of criminal networks and providing assistance to victims.
\end{abstract}

Keywords: economic inequality; international cooperation; international security; organ trafficking; organized crime; international security.

Resumo. As guerras internas e regionais, a iniquidade e a instabilidade dos governos podem incrementar o tráfico ilegal de órgãos e tecidos de origem humano. Como resultado deste tipo de mercado ilegal, têm-se financiado organizaçóes criminais que representam um risco para a paz e segurança internacional. A comunidade internacional tem promovido acordos e protocolos para diminuir este crime, no entanto, estes não se têm realizado através do enfoque da segurança. As falhas na luta contra o tráfico de órgáos têm propiciado a geração de organizaçôes criminais, as quais buscam enriquecer-se à custa das condições de saúde das pessoas menos favorecidas no mundo. Ameaças internacionais como o Estado islâmico e outros grupos rebeldes usam o tráfico de órgãos como meio para financiar as suas atividades. Com o fim de garantir a segurança colectiva, se requerem maiores esforços na matéria legislativa que permitam fortalecer os programas desenvolvidos por instituiçóes como a Europol e a Interpol, com os quais se conseguiria a desarticulação das redes criminais e a assistência às vítimas.

Palavras-chave: cooperação internacional; crime organizado; desigualdade económica; segurança internacional; tráfico de órgáos.

Résumé. Les guerres internes et régionales, l'iniquité et l'instabilité des gouvernements peuvent augmenter le trafic illégal d'organes et de tissus d'origine humaine. Ce type de commerce illégal a permis de se financer à des organisations criminelles qui représentent un risque pour la paix et la sécurité internationale. La communauté internationale a promu des accords et des protocoles visant à réduire ce crime, mais l'approche de la sécurité n'y est pas présente. Les erreurs dans la lutte contre le trafic d'organes ont favorisé l'apparition d'organisations criminelles, qui cherchent à s'enrichir aux dépens des conditions de santé des personnes les plus défavorisées du monde. Des menaces internationales, tel l'État islamique et autres groupes rebelles ont recours au trafic d'organes pour financer leurs activités. Afin de garantir la sécurité collective, il faut faire des efforts supplémentaires en matière législative pour renforcer les programmes développés par des institutions comme l'Europol et l'Interpol, ce qui permettrait le démantèlement des réseaux criminels et l'aide aux victimes.

Mots-clés: coopération internationale ; crime organisé ; inégalité économique ; sécurité internationale ; trafic d'organes. 


\section{Introducción}

Las organizaciones criminales a nivel internacional han buscado establecer mercados que les permitan maximizar las ganancias y minimizar los controles de las autoridades de cada país. En este sentido, actualmente existen mercados ilegales de drogas, armas, productos, órganos, entre muchos otros.

El tráfico ilegal está directamente relacionado con la desigualdad económica, pues las sociedades con mayores índices de pobreza y de necesidades insatisfechas son más propensas a presentar un alto número de personas dispuestas a vender sus órganos como única forma de subsistencia o que son víctimas de la extracción de órganos de forma no consentida (Budiani-Sabare \& Karim, 2009).

Asimismo, las guerras internas y regionales, la inequidad y la inestabilidad de los gobiernos pueden incrementar el tráfico ilegal de órganos y tejidos. Además, con este tipo de mercado ilegal se han financiado organizaciones criminales que representan un riesgo para la paz y la seguridad internacionales. La comunidad internacional ha promovido acuerdos y protocolos para disminuir este crimen, pero no a través del enfoque de la seguridad. Para presentar una alternativa diferente, a continuación se sintetizan los retos que trae este crimen para la seguridad internacional.

\section{Tráfico ilegal y seguridad internacional}

A pesar de que el tráfico ilegal y la seguridad internacional son dos términos ampliamente utilizados, es importante definirlos para guiar el análisis posterior. La Unidad Especializada en Investigación de Tráfico de Menores, Personas y Órganos (2015) del gobierno mexicano afirma que

[e]l tráfico de órganos consiste en la venta, donación y transporte de órganos con el fin de obtener un beneficio económico, ya sea que el pago sea realizado por la persona a quien se le realizará el trasplante o el beneficio que se obtenga por parte de miembros de las organizaciones delictivas que estén bien estructuradas para la obtención ilegal de los órganos que serán vendidos a hospitales o médicos que realizan los trasplantes clandestinamente.

La definición que presenta el gobierno mexicano establece dos tipos de tráfico de órganos: el primero es producto del hurto de los órganos por parte de organizaciones criminales, mientras que el segundo hace referencia a la disposición de una persona a vender sus órganos a cambio de un beneficio económico. Respecto a este último, cabe mencionar que algunas regiones del mundo tienen una mayor cantidad de personas que participan voluntariamente de ese tráfico, de tal manera que en estos lugares se promueve el conocido turismo de órganos ${ }^{1}$.

$\overline{1}$ Término acuñado en la Declaración de Estambul sobre el tráfico de órganos y el turismo de trasplantes. 
La definición de la seguridad internacional, por su parte, presenta una dificultad mayor. Si bien cada teoría de las relaciones internacionales considera distintos aspectos en esta definición, es posible afirmar que la posguerra fría marcó el inicio de la seguridad internacional como objeto de estudio y que, una vez terminó el conflicto disuasivo entre Occidente y Oriente, proliferaron los actores determinantes en el sistema internacional. A partir de este punto, el concepto ha tenido mutaciones proporcionales a los cambios coyunturales del contexto mundial.

El concepto de seguridad se muestra como una idea organizativa sobre los distintos fenómenos de la globalización, desplegando un programa de investigación que va más allá de las presunciones realistas del poder militar o de los principios idealistas de la investigación por la paz. (Orozco, 2006, p. 161)

Debido a los cambios intranacionales y a las divisiones ideológicas que perduraron luego de la Guerra Fría, distintos actores extranjeros buscaron ampliar su zona de influencia con el fin de maximizar sus beneficios, lo cual incrementó las amenazas nacionales. En este sentido, la seguridad internacional se entiende $\mathrm{como}^{2}$

un sistema de seguridad que tenga como referente la gestión de los asuntos públicos mundiales, y que implique un replanteamiento de la seguridad colectiva enfocada hacia una comunidad global de principios y normas que promuevan prácticas comunes en el comportamiento internacional. (Orozco, 2006, p. 161)

La globalización ha permitido, entre muchas otras cosas, la consolidación de políticas mundiales, de manera que, frente a las grandes amenazas para uno o varios países, la comunidad internacional en conjunto ha definido estándares y lineamientos para detenerlas. Así, el terrorismo, la pobreza, las pandemias, las guerras regionales, entre muchos otros fenómenos, han sido objeto de inversión de recursos y esfuerzos de diferentes actores internacionales, los cuales han buscado controlar efectivamente la amenaza con el fin de garantizar mayores niveles de seguridad.

En este sentido, la cantidad de productos y personas que cruzan las fronteras a diario a través de rutas ilegales llevó a que la delincuencia organizada dejara de ser un problema exclusivo del país en donde tenía lugar. Al respecto, la Oficina de las Naciones Unidas Contra la Droga y el Delito (Unodc, s. f.) manifiesta su preocupación:

Se trata de redes delictivas organizadas fluidas que se benefician de la venta de productos ilegales siempre que haya demanda de ellos. Esos mercados ilegales internacionales son anónimos y más complejos que nunca, y cada año generan miles de millones de dólares.

2 La definición es considerada como la más apropiada para el análisis, no necesariamente la más completa ni mucho menos la única. 
Específicamente, la venta de órganos se ha estudiado como parte del tráfico de personas y como un delito conexo al tráfico de migrantes. En ambos casos, las víctimas comparten un perfil similar, lo cual no solo permite identificar las zonas con mayor vulnerabilidad, sino que además les ha facilitado a los países acoger las estrategias adecuadas para mitigar el riesgo.

Una de las debilidades frente a la lucha contra el tráfico de órganos es precisamente analizarlo como un crimen conexo a los demás delitos transaccionales (como el tráfico de drogas, el contrabando, entre otros), ya que esta perspectiva hace difícil que sea comprendido como fuente de la criminalidad, la alteración del orden público interno y la revaluación de conceptos como la soberanía y las fronteras (Samper, 2009).

De esta forma, cada uno de los Estados involucrados en la cadena de crimen se ve obligado a replantear su seguridad en dos aspectos principales: i) fortalecer la seguridad interna, de modo que tenga la posibilidad de desarticular las organizaciones criminales (o sus facciones) en cada uno de los países y ii) coordinar la cooperación en materia de defensa, no solo para facilitar la desarticulación total de las organizaciones criminales, sino también para apoyar a las víctimas.

La cooperación internacional ha promovido prácticas comunes que han sido respaldadas por los gobiernos nacionales, lo cual ha permitido que se generen mecanismos para garantizar el cumplimiento de los acuerdos internacionales. Los diferentes foros que han realizado la Organización de las Naciones Unidas (ONU), la Unión Europea y las organizaciones internacionales interesadas han hecho posible que se lleve un control mucho más estricto a las cadenas de tráfico, y, por ende, que se genere un mayor impacto en su disminución (Unodc, s. f.).

Se observa, entonces, que la definición de seguridad internacional propicia un marco conceptual en el cual el tráfico de órganos cumple con las condiciones necesarias para que sea incluido en la agenda internacional. Por esta razón, analizar las rutas de acción necesarias para contrarrestar sus efectos es una tarea que deben realizar las naciones.

La importancia de identificar la relación entre la seguridad internacional y el tráfico de órganos no consiste únicamente en el cumplimiento de las condiciones para el análisis, sino también en la fuerte conexión entre el área de estudio y el crimen analizado, así como en la falta de desarrollo académico que ha tenido este tema. Por lo tanto, se trata de un espacio de innovación en materia de defensa que busca fortalecer, a partir de las prácticas comunes para otros delitos transnacionales, la lucha contra el tráfico de órganos y tejidos.

\section{Características generales del comercio ilegal de órganos}

El comercio ilegal de órganos se ha caracterizado porque tiene una demanda paradójica: debido a la baja oferta de donaciones altruistas (voluntarias y no remuneradas) y a la alta demanda de diferentes tipos de órganos, se ha creado un ciclo de oferta y demanda que ha promovido la ilegalidad (Matesanz, 1994). 
La disminución constante de la cantidad de órganos disponibles crea dos escenarios: en primer lugar, se podría incrementar el número de personas dispuestas a pagar bien al donante directamente (turismo de órganos), lo cual afectaría directamente la cantidad de personas dispuestas a asumir el riesgo que implica la donación sin recibir una remuneración. El segundo escenario posible se presenta cuando se contacta a un tercero para que cometa el delito de tráfico de órganos, lo cual disminuirá el número de personas dispuestas a donar un órgano, al tiempo que aumentará el de quienes accedan a estos servicios como último recurso para salvar sus vidas.

Como en la mayoría de productos del mercado ilegal, no se tienen datos exactos sobre la cantidad de órganos traficados a nivel internacional. Sin embargo, la Organización de las Naciones Unidas, en un intento por establecer un control a este delito, solicitó a los Estados información cuantitativa referente al tráfico de órganos y tejidos para consolidar una base de datos mundial. No obstante, esta iniciativa no se pudo completar debido a la insuficiencia de los datos entregados (Makei, 2015).

Según la Unodc (s. f.), el modus operandi de las organizaciones criminales que trafican órganos puede tener cinco variaciones, de acuerdo con los datos que arrojaron los testimonios de las víctimas: en primer lugar, se encuentra el grupo de personas que acuerdan la venta de alguno de sus órganos a cambio de una suma monetaria importante ${ }^{3}$. En segundo lugar, las víctimas que acceden voluntariamente son engañadas por un médico que no aclara las consecuencias, riesgos y cuidados necesarios después de la cirugía. En tercer lugar, los "dadores" ${ }^{\text {s }}$ son víctimas de extorsiones o presiones de terceros con el fin de que accedan a este tipo de procedimientos. En cuarto lugar, la forma más reportada en el mundo consiste en que las víctimas son anestesiadas sin consentimiento para realizar el procedimiento. Finalmente, en quinto lugar, como producto del turismo de órganos, miles de personas se someten a procedimientos en condiciones no óptimas, con lo cual ponen en riesgo sus vidas (Unodc, 2011).

A pesar de que este problema les compete a todos los países, en el marco de la ONU se han estudiado los casos de Kosovo y Pakistán, con el fin de dilucidar la relación real entre los conflictos armados, las crisis económicas, sociales y políticas y el tráfico de órganos.

\section{Pakistán}

La transición democrática de Pakistán inició en 2008 con la caída de Musharraf, sin embargo, debido a que la institución estatal más fortalecida es el Ejército Nacional, el cual goza de un presupuesto más alto que los destinados a la educación y la salud juntos, sin importar el partido o la fuerza política que esté en el poder, es el poder militar el que tiene una mayor influencia dentro del sistema político (Mato, 2011).

3 En muchos de estos casos, las personas no reciben la cantidad de dinero inicialmente pactada, por lo cual se considera la transacción como una estafa.

4 Persona a la que se le extrae el órgano. 
En 2010, el territorio paquistaní sufrió fuertes inundaciones a causa de las constantes lluvias. La fuerte crisis sanitaria y social desatada por el desastre natural agravó las difíciles condiciones geográficas y la falta de cobertura del gobierno nacional. Además, aunque a través de la cooperación se ofrecieron diferentes apoyos económicos internacionales al gobierno iraquí, los altos niveles de corrupción del país llevaron a los organismos internacionales a suspenderlos.

Mientras la mayoría de las instituciones flaqueaba en su ejercicio, el Ejército paquistaní lideró las ayudas a las víctimas, ejercicio que aumentó las críticas y la desestabilidad del gobierno de Asif Alí Zardari, quien fue criticado por la prensa con motivo de sus constantes ausencias y corrupción (Mato, 2011).

Posteriormente, en 2011, el Comité Internacional de la Cruz Roja (CICR) hizo un llamado de atención a Pakistán con el fin de que se solucionaran los problemas relativos a la inseguridad, entre los cuales se citaron: las operaciones militares por parte de organizaciones no estatales, el desplazamiento interno, la baja presencia de organizaciones internacionales y el poco apoyo a la Media Luna Roja y otras organizaciones no gubernamentales (ONG) que buscaban prestar atención integral a las víctimas del conflicto (CICR, 2011).

De la misma forma, los conflictos fronterizos han afectado negativamente la productividad de los suelos y han generado una crisis alimentaria que ha aumentado los índices de vulnerabilidad de los ciudadanos. Como consecuencia, se han incrementado el número de pakistaníes que migran en busca de mejores oportunidades y las transacciones de pago de renta.

En los últimos años, Pakistán se ha convertido en uno de los mercados más grandes de órganos del mundo. $\mathrm{Al}$ respecto, el diario El País afirma:

De los 2.000 riñones que se trasplantan al año en Pakistán, dos terceras partes tienen destinatarios extranjeros. Provienen de campesinos que viven en condiciones de insalubridad y pobreza extremas. Ganan sueldos de miseria: una media de 15 dólares al mes. Se ven obligados a pedir anticipos a sus terratenientes. Acaban adquiriendo deudas de tal magnitud, que se heredan de padres a hijos. Son esclavos del siglo XXI. (López, 2009)

De esta forma, se evidencia que existe una relación entre la pobreza y la venta de órganos. También se debe tener presente que, además, las condiciones ambientales y económicas han eliminado otras formas de obtención de los recursos necesarios para la subsistencia. El Instituto de Urología y Trasplante de Karachi, Pakistán, al analizar la venta de rińones encontró que el 39,7 \% de los "dadores" son responsables de entre cuatro y cinco personas, mientras el 31,5\% de entre seis y siete personas, lo cual incrementa la vulnerabilidad de los pakistaníes (Anwar et al., 2007).

Pakistán es un caso especial porque tiene problemas internos de representación, violencia y corrupción, además de que sostiene conflictos fronterizos con India y Afganistán, lo cual dificulta una acción colectiva en contra del delito de tráfico de órganos. Por lo 
tanto, analizar este contexto particular permite plantear una disyuntiva frente a la prohibición del tráfico de órganos, ya que este se ha convertido en un medio necesario para someter a las clases menos favorecidas.

Sin embargo, el problema del tráfico de órganos no es exclusivo de esta región, pues a lo largo del planeta diferentes países están implicados en alguna fase de esta cadena delictiva. Al respecto, casos como el de Kosovo muestran la internacionalización del problema.

\section{Kosovo}

En Kosovo, la inestabilidad que ha generado los movimientos independentistas y la oposición regional sobre este proceso político ha dejado no solo miles de personas desamparadas y en condiciones de vulnerabilidad, sino también ha producido un gran número de desapariciones y violaciones a los Derechos Humanos, entre las cuales se encuentra el tráfico de órganos.

3. Según la información reunida por la Asamblea y las investigaciones penales en curso, numerosas indicaciones concretas y convergentes confirman que algunos serbios y algunos albanokosovares fueron detenidos en lugares secretos de detección bajo el control de ELK [Ejército de Liberación de Kosovo] en el norte de Albania y fueron sometidos a trabajos inhumanos y trato degradante, antes de que fueran desaparecidos.

4. Numerosos indicios permiten confirmar que, durante el periodo inmediatamente posterior al final del conflicto armado, antes de que las fuerzas internacionales realmente hubieran podido tomar el control de la región y restablecer la ley y el orden, a algunos presos les extrajeron órganos en una clínica ubicada en territorio albanés, cerca de Fushë-Krujë, con el propósito de enviarlos al exterior para ser trasplantados. (Consejo Europeo, 2010; traducción propia)

El gran desafío en la lucha contra el tráfico de órganos es disminuir las condiciones de desigualdad, ya que mientras las personas estén dispuestas a pagar por un trasplante ilegal de órgano, las redes criminales estarán motivadas en abusar de las personas más necesitadas con el fin de enriquecerse de forma ilegal.

\section{Características generales}

Los distintos estudios, tanto generales como particulares, han demostrado que las víctimas tienen condiciones similares, lo cual permite plantear una serie de características a partir de las cuales es posible formular exitosamente políticas y estrategias para mitigar el riesgo de criminalidad a nivel internacional.

La Europol, como parte de la lucha contra este flagelo, ha encontrado que las personas con mayor probabilidad de ser víctimas de este delito tienen las siguientes características: tienen entre 18 y 30 años, provienen de ciudades pequeñas o pueblos, tienen bajos niveles de educación y están en condición de desempleo. Además, al analizar el perfil 
psicológico de las víctimas, la institución encuentra como rasgo general que han sufrido violencia, tanto en sus países de origen como en el ámbito familiar. Otras condiciones adicionales de vulnerabilidad son la drogadicción, alcoholismo, núcleos familiares disfuncionales, entre otras (Europol, 2011).

Asimismo, se ha encontrado que la condición de migrante es un factor incidente en las estadísticas sobre víctimas. En primer lugar, se nota cómo el "dador" ve el tráfico de órganos como una salida a los conflictos y necesidades, por lo cual es más propenso a incurrir en la migración ilegal. En segundo lugar, una vez el migrante ilegal esté ubicado en el continente europeo, sus niveles de vulnerabilidad aumentan debido a la dificultad que tiene para conseguir trabajo y sustento.

Por su parte, las organizaciones criminales a cargo del tráfico ilegal también comparten similitudes: se han constituido como múltiples redes pequeñas en constante interacción con otras organizaciones criminales. Ya se mencionó antes cómo la mayoría de países en el mundo están involucrados en este tipo de delitos, ya que la organización criminal requiere de los servicios de varias personas ubicadas en diferentes espacios para completar los traslados internacionales.

De acuerdo con la Europol, un aspecto importante que comparten estas organizaciones es que tienen personas encargadas de cada fase del tráfico, a saber: el reclutamiento, el transporte, la documentación falsa necesaria para el procedimiento, así como personas encargadas de completar los procesos de corrupción para evitar la desarticulación de la organización (Europol, 2011).

\section{Respuestas legales y políticas de seguridad}

El tráfico ilegal de órganos, como se ha presentado, no solo representa una amenaza a la seguridad nacional y regional de los países más inestables del mundo — como parte de la respuesta que tiene la sociedad a la vulnerabilidad provocada por el funcionamiento de las instituciones-, sino que se ha convertido en un delito transfronterizo y, por ende, una amenaza internacional. No obstante, no se ha logrado establecer un marco legal que permita formalizar la lucha internacional contra este tráfico5.

No existe un acuerdo universal sobre la definición del delito de tráfico de órganos ni tampoco una herramienta relevante que sea universal y legalmente vinculante. La carencia de ambos no implica que el delito sea insignificante, sino que refleja su naturaleza emergente, por lo que la comunidad internacional está empezando ahora a entender su alcance. (Makei, 2015, p. 91)

$5 \mathrm{Al}$ ser tratado como una parte de la trata de personas, el tráfico de órganos forma parte de las convenciones internacionales, como el Protocolo de Palermo, entre otros. Estos no serán reseñados con el fin de ahondar en las estrategias dirigidas únicamente al tráfico de órganos. 
A pesar de esto, en el 2008 se convocó a los gobiernos y las autoridades médicas con el fin de analizar el incremento en el tráfico de órganos. Como producto de esta reunión, se estableció la Convención de Estambul, con la cual se busca reglamentar la legalidad de los procesos y definir una ruta de acción para que cada país no solo disminuya de forma interna la oferta y demanda de estos servicios, sino que además emprenda la lucha contra las bandas criminales organizadas.

De la misma forma, a partir de la red de intercambio de datos que ha creado la Interpol, se han establecido estrategias para fortalecer las actividades policiales. La intervención de esta institución ha permitido mejorar el trabajo de los agentes fronterizos - quienes podrán detectar las rutas y las organizaciones detrás del cruce transfronterizo de "dadores" - y ha apoyado la actividad operacional interna que lleva a incrementar los niveles de seguridad en las regiones más afectadas (Interpol, 2016).

La Interpol ha combatido el tráfico de órganos - como parte de la trata de personas- con cuatro estrategias: i) la formulación de una base de datos que permita establecer los lugares más propensos y recurrentes en el turismo de órganos; ii) la definición de estrategias de cooperación a partir del uso de esta base de datos; iii) debido a la transversalidad de este crimen, la institución ha promovido el control de la migración ilegal como medida para disminuir las víctimas del tráfico de órganos, y, finalmente iv), ha establecido canales para difundir las consecuencias legales en diferentes países y, de esta manera, desestimular el interés de las personas en participar en la cadena delictiva.

Por su parte, la Unión Europea ha promovido la cooperación en el bloque con el fin de impulsar medidas que combatan el crimen y conocer el estado real del tráfico de personas para extraer sus órganos. Las estrategias del bloque abarcan desde la cooperación judicial hasta la prevención y atención de las víctimas; cada uno de estos esfuerzos es coordinado por la Europol, incluyendo entonces la lucha contra las organizaciones criminales (Comisión Europea, 2012).

En este contexto, a través de sus instituciones, la Unión Europea ha establecido un plan de acción para guiar la lucha contra este delito, el cual plantea cinco prioridades:

a) Identificar, proteger y asistir a las víctimas del tráfico; b) fortalecer la prevención del tráfico de personas para la extracción de órganos; c) incrementar las sanciones contra los traficantes; d) promover la coordinación y cooperación entre los actores clave y las políticas coherentes; e e) incrementar el conocimiento y la respuesta de las preocupaciones emergentes relacionadas con todas las formas de tráfico de personas. (Comisión Europea, 2012)

En materia de seguridad, la Estrategia de Seguridad Interna de la Unión Europea ha promovido distintos planes de atención a temas como la migración; no obstante, al no ser vinculante, el éxito de la estrategia planteada por el bloque depende en gran manera de la cooperación de los Estados miembros y de su voluntad para responder al llamado 
a construir leyes que eliminen los vacíos jurídicos por medio de los cuales se justifica el tráfico (Comisión Europea, 2012).

El compromiso europeo con la lucha contra el tráfico de órganos se puede considerar como positivo, teniendo en cuenta que se ha establecido un plan de trabajo de cuatro años. Esto permite dilucidar la creación de una política sólida en el tiempo, la cual ha surgido del análisis de los resultados de políticas previas; adicionalmente, la transversalidad con la que se han desarrollado los esfuerzos lleva a una mayor comprensión de las implicaciones que tiene este crimen a nivel internacional.

Producto del análisis realizado en 2015, en Santiago de Compostela se llevó a cabo la Conferencia Internacional contra el Tráfico de Órganos, en la cual se redactó y firmó el Convenio Internacional contra el Tráfico de Órganos, suscrito por catorce países y a la espera de la ratificación en los diferentes Estados. María Lagoa (2015) reporta que dicho acuerdo pretende

establecer como delito la extracción ilícita de órganos humanos procedentes de donantes vivos o fallecidos y su uso para trasplantes o para otros fines. Busca mejorar la transparencia de los sistemas nacionales y garantizar un acceso equitativo a los trasplantes. La prevención y la autosuficiencia en esta lucha son otros de sus objetivos. También establece que las partes habrán de adoptar las medidas legislativas ( $\mathrm{y}$ otras que fueran necesarias) para garantizar el acceso a la información, la asistencia y el derecho de compensación a las víctimas.

Este acuerdo tiene como principal beneficio que facilita la cooperación en materia de defensa y de seguridad: al compartir márgenes legislativos y procedimentales, las acciones colectivas para detener este crimen transnacional rendirán mayores resultados, lo que a su vez se evidenciará en la desarticulación de las organizaciones criminales. Asimismo, este tipo de acuerdos sientan los precedentes para establecer una estrategia internacional, ya que la eliminación de este delito tardará más de lo esperado si cada Estado lo aborda desde una perspectiva diferente.

Por su parte, el grupo de trabajo de trata de personas de la ONU presentó en 2011, con motivo de la Conferencia de las Partes en la Convención de las Naciones Unidas contra la Delincuencia Organizada Transnacional, un documento de antecedentes en el cual no solo se llama a los gobiernos a solucionar los problemas generadores de este delito ${ }^{6}$, sino que además brinda guías para el desarrollo legislativo y para los parlamentarios (Organización de las Naciones Unidas [ONU], 2011).

También cabe mencionar que la Iniciativa Global para la Lucha contra el Tráfico de Órganos lanzó una campaña denominada Think Globally, Act Locally, en la cual se resalta la importancia que tiene conservar las iniciativas globales que consideren la internaciona-

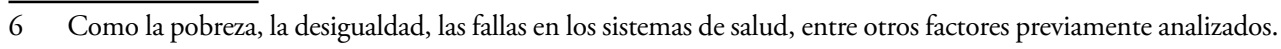


lización del delito, al tiempo que generen acciones locales que permitan actuar teniendo en cuenta las particularidades del país o región.

Como ejemplo, a continuación se analizan dos casos particulares de acciones legislativas que han buscado responder a los desafíos planteados por el desarrollo de este delito en el campo internacional. Se tomará entonces la legislación dominicana y española con el fin de anotar cómo la localización de un país en la cadena de tráfico afecta su posición e intereses.

En el año 2003, la República Dominicana promulgó la Ley 137-03 sobre el Tráfico Ilícito de Migrantes y la Trata de Personas. En primer lugar, el título de la ley evidencia que el tráfico de órganos se considera una división de la trata de personas y del tráfico de migrantes. Asimismo, el lenguaje utilizado en la ley permite ver que el desarrollo legislativo responde a la preocupación internacional por el fenómeno de la migración ilegal.

El tráfico de órganos se considera como la más remota de las posibilidades, y no se delimitan estrategias particulares para detectar el crimen; las penas se definen entre los diez y los quince años, al tiempo que se reconoce la existencia de organizaciones criminales a las cuales se les atribuye responsabilidad penal sobre el delito. El consentimiento que el "dador" entrega al intermediario, a pesar de no ser desarrollado dentro de las definiciones, se estipula como un argumento no excluyente de la responsabilidad legal del acusado (Ley 137-03, 2003).

También se destaca de esta ley que no reconoce el papel del Estado ni su responsabilidad en la cadena delictiva, de manera que se trata de un marco legal insuficiente, sobre todo porque desde su promulgación, hace trece años, la transformación de los matices del crimen y de sus ejecutores demandan hoy en día una mayor profundidad en la legislación.

España, por su parte, a través de la Ley Orgánica N. ${ }^{\circ} 5$ de 2010, introdujo como delito el tráfico de órganos:

Como respuesta al fenómeno cada vez más extendido de la compraventa de órganos humanos y al llamamiento de diversos foros internacionales a abordar su punición, se ha incorporado como infracción penal la obtención o el tráfico ilícito de órganos humanos, así como el trasplante de los mismos. (Ley Orgánica N.o 5, 2010)

Con esta ley, el gobierno español respondió al compromiso del bloque europeo para definir la legislación particular del tráfico de órganos, entendiendo que, si bien por su naturaleza este no se desliga de la trata de personas, por su particularidad debe ser considerado como individual.

A pesar de la fuerte crisis que afrontó España hace unos años, se considera que las condiciones de vida de los españoles son superiores a la de los países de los cuales generalmente provienen los "dadores". Si se entiende este hecho y se tiene presente la realidad social y económica de la España de 2010, entonces toma importancia el reconocimiento de su papel como "importador" de estos órganos y la penalización de este tipo de comportamientos. 
2. Si el receptor del órgano consintiera la realización del trasplante conociendo su origen ilícito, será castigado con las mismas penas que en el apartado anterior, que podrán ser rebajadas en uno o dos grados, atendiendo a las circunstancias del hecho y del culpable. (Ley Orgánica N. ${ }^{\circ} 5,2010$ )

Entre las características de la legislación se encuentra que se excluyen los tejidos y las células, con lo cual se crean vacíos que podrán ser aprovechados por las organizaciones criminales. Sin embargo, la ley es amplia en castigar todas las conductas no respetuosas de las regulaciones para el trasplante de órganos, sobre todo en relación con la obtención del órgano.

Al comparar las dos legislaciones mencionadas, se nota que los países en donde es más común la compra de órganos tienen un mayor compromiso por entender el tráfico de órganos como un delito internacional. Sin embargo, las acciones en defensa requieren una legislación previa, de manera que no tendría ningún sentido desplegar grandes operaciones policiales frente a un delito no tipificado o cuyo proceso, por los vacíos en la legislación, sea fácilmente archivado.

Fortalecer los procesos internos para establecer leyes funcionales se ha convertido en la única alternativa para eliminar los vacíos jurídicos que existen en torno a este delito. Al respecto, cabe mencionar que las organizaciones internacionales han esbozado proyectos que sancionan el tráfico de órganos, por ejemplo, la Organización Mundial de la Salud, el Consejo de Europa, la Comunidad de Estados Independientes y el Consejo Iberoamericano de Donación y Trasplante han aportado estudios suficientes para entender la realidad del tráfico de personas como un problema social, médico, político y de seguridad (ONU, 2011).

Sin embargo, debido al enfoque con el que se ha tratado esta problemática, los esfuerzos particulares en materia de seguridad para luchar contra el tráfico de órganos son compartidos con otros delitos, es decir, no se han desarrollado estrategias de defensa particulares ni exclusivas para afrontarlo, de ahí que constituya una necesidad internacional.

\section{Retos para la seguridad internacional}

A partir del análisis anterior, es posible identificar cinco retos principales para la seguridad internacional: i) la inestabilidad de los gobiernos de países en desarrollo, ii) el aumento de migrantes, iii) las acciones del autoproclamado Estado Islámico, iv) la articulación entre las acciones colectivas contra las organizaciones criminales y $v$ ) las legislaciones internas de los diferentes países — adhesión de compromisos vinculantes-.

Como se ha analizado antes, la desigualdad y la pobreza se han convertido en factores propicios para el tráfico de órganos, por lo que, típicamente, los "dadores" provienen de zonas en conflicto o países en vía de desarrollo, mientras los "receptores", usualmente, pertenecen a países más desarrollados. Al respecto, Matesanz (1994) afirma que 
[1] os centroeuropeos, alemanes fundamentalmente, viajan también a Extremo Oriente y en los últimos años a Europa del Este; los norteamericanos parecen más centrados en donantes de Latinoamérica. $\mathrm{Al}$ parecer, ha habido igualmente algún caso aislado de enfermos españoles trasplantados en Latinoamérica con donante vivo local. Enfermos de países árabes son trasplantados en algunos emiratos con donantes locales o más directamente hindúes. (p. 635)

La inestabilidad de los gobiernos en Oriente Medio y el norte de África, así como la consecuente migración ilegal con destino a Europa Occidental, ha incrementado la cantidad de personas en condición de vulnerabilidad en sus países de origen y el número de migrantes ilegales, quienes son un grupo recurrente en este delito. Por lo tanto, en materia de seguridad internacional, se deben fortalecer no solo los controles, sino también las condiciones de los migrantes que a diario buscan ingresar al territorio europeo.

La legislación internacional se enfrenta, entonces, a una nueva forma de esclavitud, a la cual están expuestas miles de personas que diariamente buscan huir de la pobreza y la guerra, quienes en muchos casos son esclavizados o vendidos por órganos en países como Israel. Así, lo reportó CNN:

Un líder de Sawarka dijo que era consciente de que en el Sinaí estaba ocurriendo la trata de personas y que, en algunos casos, los refugiados eran sometidos a trabajos forzados y torturados. Sin embargo, agregó que solo los elementos deshonestos de su tribu estaban involucrados. (Pleitgen \& Fadel, 2011; traducción propia)

No obstante, esta no es la única región afectada. En los últimos años México se ha convertido en objeto de crítica por las constantes denuncias de robo de órganos y abuso a los migrantes, de manera que se deben desarrollar medidas que mitiguen la vulnerabilidad de los migrantes y les garanticen mejores condiciones de vida que las que tienen en sus países de origen.

Asimismo, los grupos terroristas, como el autoproclamado Estado Islámico, han legalizado la extracción ilegal de órganos en sus zonas de influencia: "Si los juristas han permitido, cuando sea necesario, el consumo de carne humana para evitar la muerte, resulta incluso más apropiado trasplantar órganos de infieles en cuerpos de musulmanes" (Carrión, 2016).

Los actos terroristas perpetrados por el Estado Islámico son a todas luces contrarios a los Derechos Humanos y a los valores protegidos por los sistemas políticos de Occidente. La legalización del tráfico de órganos como medida para salvar las vidas de los combatientes es uno de los más grandes retos para la seguridad internacional, debido al uso de hospitales como resguardo y centro de atención de heridos, que a su vez funcionan abiertamente como espacios de extracción ilegal de órganos.

Se debe considerar que antes de la nueva política del Estado Islámico se presentaban disyuntivas fuertes frente al ataque de este tipo de instalaciones protegidas por el Derecho Internacional Humanitario, las cuales presuntamente eran usadas para almacenar armas 
y acuartelar hombres. A esto se le suma la certeza de que en estos centros se violan los derechos de personas consideradas como traidores y tienen lugar asesinatos sistemáticos a los médicos que se nieguen a acatar las órdenes de extracción de órganos.

Adicionalmente, el diario El Mundo reporta que gran parte de los órganos extraídos se transporta con el fin de venderlos, de manera que se convierten en una fuente de financiamiento del grupo terrorista. De haber un marco legal que permita una acción policial colectiva y fructífera, como mínimo se podría ejercer presión para evitar el comercio que ha instaurado el Estado Islámico (Carrión, 2016).

Para la seguridad internacional, la articulación entre las acciones colectivas contra las organizaciones criminales y las legislaciones internas de los diferentes países constituye uno de los mayores retos. Una vez estas dos herramientas se formalicen en el marco de una lucha internacional contra el tráfico de órganos, se incrementarán los resultados en materia de seguridad.

La condición principal para desarticular estos grupos criminales es que sea obligatoria la adopción de marcos legales sólidos. Se ha visto cómo la comunidad internacional ha desplegado - a través de las instituciones de seguridad internacional y nacional — el uso de todas las herramientas a su alcance, sin que haya logrado contener el aumento de las cifras de víctimas. Esto se debe a que los instrumentos implementados no son vinculantes (Kelly, 2013).

La expansión y el fortalecimiento de las redes criminales son producto de las debilidades institucionales de los gobiernos en las regiones más afectadas. Es claro que dichas organizaciones criminales no se dedican exclusivamente al tráfico de órganos y que encuentran en las condiciones sociales y económicas nuevas formas de aprovechar las rutas ilegalmente construidas.

Para garantizar la seguridad colectiva es necesario la adhesión de compromisos vinculantes que permitan establecer una lucha frontal contra estas organizaciones, de manera que se incrementen los niveles de seguridad a través de la desarticulación de estas redes y se aprovechen los canales de comunicación con otras organizaciones criminales para afectar otros tipos de mercados ilegales (Samper, 2009).

Sin embargo, los compromisos vinculantes deben responder no solo a la detención de las organizaciones criminales, sino también a alcanzar de forma efectiva el desarrollo sostenible y eliminar las reales causas que provocan el tráfico de órganos. En suma, las condiciones sociales deben mejorar para evitar que las personas se vean obligadas a vender sus órganos como medio de subsistencia.

\section{Conclusiones}

El tráfico de órganos se ha convertido en una preocupación mayor para la comunidad internacional. Si bien inicialmente se analizaba como una problemática de competencia exclusiva de las autoridades sanitarias, hoy en día se debe investigar este delito de forma transversal debido a la complejidad que ha adquirido. 
Como parte del análisis, se han encontrado unas características similares entre los "dadores": la pobreza, la migración, las guerras internas y regionales, así como la responsabilidad de un núcleo familiar amplio, entre otras, han permitido que las personas sean disuadidas u obligadas a vender uno de sus órganos como última medida, en la mayoría de los casos sin conocer de forma completa las consecuencias que tiene el procedimiento.

Alrededor del mundo se han creado redes criminales que aprovechan la escasez de oferta de órganos legales para fungir como intermediarias de esta cadena ilegal, que no solo prestan estos servicios, sino que además se enriquecen a través de nuevas formas de esclavitud, como la sujeción de personas en trabajos forzosos o en redes de prostitución, y en algunos casos no responden con los pagos inicialmente pactados.

Sin embargo, en el mercado también existen organizaciones terroristas como el Estado Islámico, que de forma no consentida extraen los órganos de presos políticos acusados de traición. Específicamente, en el norte de África se han presentado casos de abuso por parte de este tipo de organizaciones, las cuales han fabricado rutas de venta de órganos extraídos de los migrantes que causa la guerra.

También cabe destacar que se ha dado una lucha internacional a través de instrumentos no vinculantes y del compromiso parcial de algunos Estados. No obstante, aunque a través de estos sistemas se han mejorado las condiciones de las víctimas y se ha prevenido la utilización de estos mercados, el tráfico se ha sostenido y se ha convertido en una práctica común porque estas iniciativas no tienen una condición vinculante.

Analizando no solo la realidad del tráfico, sino también las legislaciones internas y los programas internacionales, se encuentran cinco retos principales para la seguridad internacional, a saber: $i$ ) la inestabilidad de los gobiernos de países en desarrollo, $i i)$ el aumento de migrantes, iii) las acciones del autoproclamado Estado Islámico, iv) la articulación entre las acciones colectivas contra las organizaciones criminales y $v$ ) las legislaciones internas de los diferentes países —adhesión de compromisos vinculantes-.

El tráfico de órganos debe entenderse como un delito internacional, de manera que para combatirlo se requiere una coalición internacional que permita establecer unos lineamientos claros para el desarrollo de la cooperación, sustentada en legislaciones internas sólidas y funcionales.

\section{Agradecimientos}

De la manera más atenta reconozco el apoyo irrestricto, la colaboración y el seguimiento que me brindaron el Departamento de la Maestría en Seguridad y Defensa Nacionales de la Escuela Superior de Guerra y el Ceeseden, ya que, sin su concurso, muy difícilmente podría haber logrado los alcances de esta investigación. Agradezco especialmente al señor Coronel de la Reserva Activa Pedro Pablo Moreno Jiménez, como director de la Maestría, y al Dr. Jonathan Jiménez y Carlos Ardila, tutores temáticos de mi trabajo y quienes para la fecha fungían como investigadores del Ceeseden. 


\section{Declaración de divulgación}

El autor declara que no existe ningún potencial conflicto de interés relacionado con el artículo, vinculado al proyecto de investigación "Desafíos y nuevos escenarios de la seguridad multidimensional en el contexto nacional, regional y hemisférico en el decenio 2015-2025", perteneciente al grupo de investigación Centro de Gravedad, de la Escuela Superior de Guerra.

\section{Financiamiento}

El autor no declara fuente de financiamiento para la realización del artículo.

\section{Sobre el autor}

Diego Eduardo Canales Rodríguez es profesional en Ciencias Militares de la Escuela Militar de Cadetes "General José María Córdova” y administrador de empresas de la Universidad Cooperativa de Colombia. MSc en Seguridad y Defensa Nacionales de la Escuela Superior de Guerra.

\section{Referencias}

Anwar, A., Mazhar, N. \& Hasan. (2007). A socioeconomic survey of kidney vendors in Pakistan. Transplant International, 20 (11), 934-939.

Budiani-Sabare, D. \& Karim, K. (2009). Los determinantes sociales del tráfico de órganos: una reflexión sobre la inequidad social. Medicina Social, 4 (1), 52-55. Recuperado de http://www.medicinasocial. info/index.php/medicinasocial/article/view/292/590

Carrión, F. (27 de febrero de 2016). Tráfico de órganos en el Estado Islámico. El Mundo. Recuperado de: http://www.elmundo.es/internacional/2016/02/27/56d1d0e146163fbe148b464b.html

Comisión Europea. (2012). The EU Strategy towards the eradication of trafficking in human beings 20122016 [documento en línea]. Recuperado de https://ec.europa.eu/anti-trafficking/sites/antitrafficking/ files/eu_strategy_towards_the_eradication_of_trafficking_in_human_beings_2012-2016_1.pdf

Comité Internacional de la Cruz Roja [CICR]. (2011). Pakistán: afrontar los numerosos problemas ligados a la inseguridad [información en página web]. Recuperado de https://www.icrc.org/spa/resources/documents/update/2011/pakistan-update-2011-05-27.htm

Consejo Europeo. (2010). Inhuman treatment of people and illicit trafficking in human organs in Kosovo [documento en línea]. Recuperado de http://www.assembly.coe.int/CommitteeDocs/2010/ajdoc462010prov.pdf

Europol. (2011). Trafficking in human beings in the European Union [información en página web]. Recuperado de http://ec.europa.eu/dgs/home-affairs/what-we-do/policies/organized-crime-and-human-trafficking/trafficking-in-human-beings/index_en.htm

Interpol. (2016). Trata de personas [información en página web]. Recuperado de https://www.interpol. int/es/Criminalidad/Trata-de-personas/Trata-de-personas

Kelly, E. (2013). International organ trafficking crisis: solutions addressing the heart of the matter. Boston College Law Review, 54 (3), 1317-1349. Recuperado de http://lawdigitalcommons.bc.edu/cgi/ viewcontent.cgi?article $=3324 \&$ context $=$ bclr 
Lagoa, M. (26 de marzo de 2015). Europa quiere extender al mundo su modelo anti-tráfico de órganos. Diario Médico. Recuperado de http://www.ont.es/prensa/Hemeroteca/DM\%20Europa\%20impulsa\%20su\%20lucha.pdf

López, M. (3 de mayo de 2009). Tráfico de órganos. Un negocio oscuro y atroz. El País. Recuperado de http://elpais.com/diario/2009/05/03/eps/1241332014_850215.html

Makei, V. (2015). El tráfico de personas por sus órganos. Revista Migraciones Forzadas, 49, 91-92.

Matesanz, R. (1994). Tráfico de órganos: hechos, ficciones y rumores. Nefrología, 14 (6), 633-645.

Mato, A. (2011). El complicado escenario interno de Pakistán tras las inundaciones [documento en línea]. Recuperado de http://realinstitutoelcano.org/wps/portal/lut/p/a0/04_Sj9CPykssy0xPLMnMz0vMAfGjzO KNg318fEKcHX1NTZz9QgKNXI0NDSBAvyDbUREAbg0Kqw!/??WCM_GLOBAL_CONTEXT=/ wps/wcm/connect/elcano/elcano_es/zonas_es/ari1-2011

Oficina de las Naciones Unidas Contra el Tráfico y el Delito [Unodc]. (s. f.). Delincuencia organizada transnacional - La economía ilegal mundializada [documento en línea]. Recuperado de https:// www.unodc.org/documents/mexicoandcentralamerica/TOC12_fs_general_ES_HIRES.pdf

Oficina de las Naciones Unidas Contra el Tráfico y el Delito [Unodc]. (2011). Conferencia de las Partes en la Convención de las Naciones Unidas contra la Delincuencia Transnacional. Trata de personas con fines de extracción de órganos [documento en línea]. Recuperado de https:/www.unodc.org/ documents/treaties/organized_crime/2011_CTOC_COP_WG4/2011_CTOC_COP_WG4_2/ CTOC_COP_WG4_2011_2_S.pdf

Organización de las Naciones Unidas [ONU]. (2011). Conferencia de las Partes en la Convención de las Naciones Unidas Contra la Delincuencia Organizada Transnacional. Recuperado de https:// www.unodc.org/documents/treaties/organized_crime/COP6/CTOC_COP_2012_15/CTOC_ COP_2012_15_S.pdf

Orozco, G. (2006). El concepto de la seguridad en la Teoría de las Relaciones Internacionales. Revista CIDOB d'Afers Internacionals, 72, 161-180.

Pleitgen, F. \& Fadel, M. (3 de noviembre de 2011). Refugees face organ theft in the Sinai. CNN. Recuperado de http://edition.cnn.com/2011/11/03/world/meast/pleitgen-sinai-organ-smugglers/

Samper, E. (2009). Seguridad colectiva: nueva política de seguridad hemisférica para América Latina. Poliantea, 5 (8), 115-134. Recuperado de http://journal.poligran.edu.co/index.php/poliantea/article/view/288/268

Unidad Especializada en Investigación de Tráfico de Menores, Personas y Órganos. (2015). Tráfico de Menores, Personas y Órganos [información en página de internet]. Recuperada de https://www. gob.mx/pgr/acciones-y-programas/unidad-especializada-en-investigacion-de-trafico-de-menores-personas-y-organos 